\title{
Actores sociales y económicos en las propuestas jurídicas y normativas de John Locke1
}

\author{
Social and economic actors in the legal \\ and normative proposals of John Locke
}

\author{
Joan Severo ChumbiTA \\ Universidad de Buenos Aires (Argentina)
}

Recibido: 13-11-2013

Aceptado: 21-02-2014

\section{Resumen}

A fin de especificar las formulaciones generales de $T . T .^{2}$ acerca de los actores sociales y económicos, se analizarán aquí ciertas propuestas jurídicas y normativas de John Locke. La lectura de la propuesta de una nueva ley de pobres ${ }^{3}$ y de la desregulación de la tasa de interés 4 (así como también otros escritos más breves) ${ }^{5}$, permitirá dar cuenta de la articulación que Locke establece por un lado entre dejar hacer a los agentes empresarios y proteger la balanza comercial y, por el otro, el disciplinamiento y la regulación de los trabajadores.

Palabras clave: Locke, propiedad, ley de pobres, desregulación.

\begin{abstract}
In order to specify the general formulations of $T$. $T$. about social and economic actors, we will discusse in this paper a number of legal and normative proposals of John Locke. The reading of the propousal of a new poor law (Draft) and the deregulation of interest rates ( $S C$, as well as other shorter writings), allow us understand Locke's articulation between, on the one hand, letting agents do business and protecting the trade balance, and on the other hand, the disciplining and regulation of workers.
\end{abstract}

Keywords: Locke, property, Poor law, deregulation.

\footnotetext{
${ }^{1}$ Este trabajo forma parte del proyecto de investigación UBACyT "El lazo colonialista en cuestión: reconfiguración de la dominación contemporánea en la figura del 'colonizado' dirigido por el Dr. Marcelo Sergio Raffin, correspondiente al área de Sociología, Programación científica 2010-2012, de la Facultad de Ciencias Sociales de la UBA.
} 


\section{Dejar hacer a los industriosos y racionales: terratenientes, manufactureros y comerciantes}

Dios dio el mundo en común a los hombres. Pero puesto que se los dio para su beneficio y las mayores conveniencias para la vida que fuesen capaces de extraer, no puede suponerse que él haya tenido la intención de que permaneciese siempre en común y sin cultivar. Él lo dio para usufructo de los hombres industriosos y racionales." John Locke6

Antes de distinguir entre los diferentes actores del capital agrario, manufacturero y comercial, es preciso aclarar el uso que se hace, en $S C^{7}$, del término comercio, así como del status general de su noción de capital. En efecto, en la medida en que Locke utiliza el término comercio tanto para referirse a la actividad comercial como a la productiva, podría cometerse el equívoco de atribuir a Locke una confusión entre ambas actividades. Sin embargo, como permite apreciar el siguiente pasaje (y como se desprende de la teoría del valor trabajo del capítulo V de T. T., II, §27-28, 40-43), Locke distingue comercialización y producción, aún cuando emplee el mismo término para ambas actividades.

El comercio puede dividirse en dos partes: 1) La manufactura doméstica, por la cual se debe entender todo el trabajo empleado por vuestro pueblo en la elaboración de materia primeras para el consumo, ya sea interno (donde se excluye la importación del extranjero) o de los extranjeros.

2) transporte, i. e., la navegación y la comercialización (Locke, 2011: 115-116).

El empleo de la misma categoría para el comercio y la producción podría atribuirse tanto a un lenguaje - o a una posición- mercantilista, o sencillamente a una rusticidad en el vocabulario económico. Sin embargo, si consideramos que el plusvalor no surge hasta tanto se concreta la venta del producto, no es del todo incorrecto utilizar un mismo término para dar cuenta de la lógica del capital. En efecto, Locke da razones para esta indistinción: "si no pueden obtener dinero a cambio de sus productos en el mercado, será imposible para ellos pagarle la renta al propietario" (Locke, 1999: 74). El capitalista manufacturero, que Locke distingue aquí con toda claridad del terrateniente, debe poder vender su producción para obtener una ganancia (véase en este sentido Marx, 1999: 474). Ganancia que, a su vez, obviamente debe ser superior a la renta.

\footnotetext{
2 Two Treatises of Government en Locke, 1824, t. IV. De aquí en más, T. T., en referencia a la obra en su conjunto, $T$. T., I para el primer tratado, $T$. T., II, para el segundo. Todas las citas serán traducidas al castellano, conservando las referencias a la edición en su lengua original.

3 Draft of a representation containing a Scheme of Methods for the employment of the Poor, Proposed by Mr. Locke, the 26th Octuber 1697 en Locke, 2003: 446-461; Locke, 2011: 191-213, de aquí en más Draft.

4 Some Considerations of the Lowering of Interest, and Raising the Value of Money en Locke, 1999: 51-159; Locke, 1824, t. IV: 1-116, de aquí en más SC.

5 "Venditio" (Locke, 2003: 442-446); "Comercio" (Locke, 2011: 115-117).

6 T. T., II, $\S 34$.

7 Some Considerations of the Lowering of Interest, and Raising the Value of Money en Locke, 1999: 51-159; Locke, 1824, t. IV: 1-116.
} 
Como se puede apreciar aquí, la perspectiva lockeana sobre la dinámica del capital es general. En este sentido, es preciso poner en cuestión la interpretación de Wood, en cuanto reduce la teoría lockeana de la propiedad a una descripción en términos de capitalismo agrario. Wood recupera así, críticamente, la interpretación de Macpherson. La interpretación de Macpherson resulta relevante aquí porque tiene el mérito de introducir a la exégesis de la teoría de la apropiación lockeana, la presencia de actores económicos con intereses enfren$\operatorname{tados}^{8}$. Sin embargo, adolece, como bien ha establecido Wood, de una proyección de los actores del siglo XIX (burguesía y proletariado urbano industrial) que no resulta adecuada al siglo XVII 9 . En este sentido, Wood hace comentarios más que pertinentes con respecto al anacronismo propio de la interpretación de Marcpherson: "Él parte de la premisa fundamental de que la Inglaterra del siglo XVII era una sociedad de mercado, sin embargo, en ninguna parte demuestra la validez histórica de esta afirmación, una equivocación decisiva, considerando las dudas de muchos comentaristas sobre la cuestión" (Wood, 1983: 7)10.

Sin embargo, una consideración exhaustiva de $S C$ tampoco permite la reducción que realiza Wood de la concepción lockeana del capital a su forma agraria. Por ejemplo, cuando Locke se refiere elogiosamente al ejemplo del ascenso de Holanda en el mercado mundial, señala que su carácter de potencia no puede atribuirse a un desarrollo capitalista agrario: "Holanda es un país donde la tierra representa una parte muy pequeña del capital11 del país" (Locke, 1999: 114). Al mismo tiempo, si consideramos la lista de factores que contribuyen, según Locke, a la riqueza del país, no encontramos en absoluto una restricción del capitalismo a la actividad agraria:

Son promotores del comercio: la libertad de comercio; la fácil naturalización; la libertad de religión; el registro o seguridad de la propiedad; las pequeñas tasas comerciales; las casas de trabajo públicas; la moneda buena, segura y difícil de falsificar; la transferencia de cuentas; el aumento y fomento de los marineros en islas ya que no hay marineros ni navegación en el continente

\footnotetext{
8 En este sentido, es importante destacar que existen diferentes antagonismos al interior del capítulo $\mathrm{V}$ de T. T., II, como por ejemplo el que surge entre una burguesía terrateniente y los nativos en las colonias, así como, en los capítulos subsiguientes, entre una burguesía industrial, comercial y financiera ascendente frente a la monarquía de inclinación absolutista (Arneil, 1992; Armitage, 2004; Becker, 1992, 654-655; Tuck, 2009, 166; Dussel, 2007: 269-282; Chumbita, 2011; Chumbita, 2014). 9 Por otra parte, Foucault también se refiere críticamente a la interpretación de Macpherson. "Suele hacerse de la emergencia del individuo en el pensamiento y la realidad política de Europa el efecto de un proceso que es a la vez el desarrollo de la economía capitalista y la reivindicación del poder político por parte de la burguesía; de allí habría nacido la teoría filosófico-jurídica que, en líneas generales, vemos desarrollarse desde Hobbes hasta la Revolución Francesa. Pero creo que, si bien es verdad que se puede ver efectivamente cierta idea del individuo en el nivel del que les hablo, también hay que ver la constitución concreta del individuo a partir de determinada tecnología de poder; y me parece que esa tecnología es la disciplina, propia del poder que nace y se desarrolla desde la edad clásica, que aísla y recorta, a partir del juego de los cuerpos, ese elemento históricamente nuevo que llamamos individuo" (Foucault, 2005b: 79).

10 Tully había dado razones similares para rechazar la interpretación de Macpherson. Sin embargo, su interpretación es completamente diferente: "en Two Treatises, Locke ofrece una justificación, no de la propiedad privada, sino que, más bien, de la comuna inglesa." (Tully, 1980:130, véase también 124125)

11 El término empleado aquí es "stock".
} 
que pueda autoabastecerse sin suministros, la mano de obra barata; las modas adaptadas a vuestra propia manufacturas; la adecuación de las manufacturas a los mercados cuyas materias primas necesitamos; las bajas tasas a la exportación de las nuevas manufacturas domésticas (Locke, 2011: 116) ${ }^{12}$.

La cita muestra con claridad la articulación entre dejar hacer al capital y establecer una posición dominante en el mercado mundial a través del intercambio de manufacturas por materias primas. En este sentido, el pasaje da cuenta de que la noción de capital que Locke maneja no puede reducirse a su forma agraria. Por otra parte, la diferencia terminológica respecto la economía clásica, no invalida la distinción conceptual entre comercio y producción (Letwin en Vaughn, 1983: 152, 73). Aquí encontramos ya la lógica liberal que viene a reemplazar al mercantilismo, y que, siguiendo a Foucault supone "una economía o un análisis económico político que integra el momento de la producción, el mercado mundial y, por fin, los comportamientos económicos de la población, los productores y los consumidores" (Foucault, 2006: 61).

Al igual que ante la ambigüedad en el uso del término comercio, se ha criticado a Locke la indistinción terminológica entre dinero y capital (Vaughn, 1983: 66). Una vez más, si bien es cierto que Locke utiliza en muchas ocasiones el término "money" tanto para referir al dinero como al capital, no se deduce de ello una incomprensión de su diferencia conceptual. En este sentido, el uso del término "stock" en referencia explícita al capital del país (del cual la tierra es una pequeña parte), no deja dudas al respecto (Locke, 1999: 114). Pero incluso en el uso indistinto del término "money", Locke comprende la diferencia entre el dinero como medida de cambio ${ }^{13}$ y como capital.

El dinero como elemento necesario para el comercio, puede ser considerado desde dos puntos de vista. Primero, como [capital] en las manos de quien paga al trabajador y al propietario de tierras [...] y si a este hombre le falta dinero (por ejemplo, al fabricante de ropa) la manufacturación no se realiza, y, por lo tanto, el comercio cesa y se pierde. $\mathrm{O}$, segundo, el dinero puede ser considerado como en las manos del consumidor, en cuyo concepto incluyo aquí al comerciante que compra mercancías manufacturadas para exportarlas (Locke, 1999: 66).

Aquí se distingue el dinero empleado por un capitalista en la actividad productiva (que paga salarios, renta y compra insumos) del dinero empleado por un consumidor directo para su abastecimiento. Por otra parte, la distinción entre terrateniente, productor y comerciante, a su vez, muestra la comprensión de la lógica del capital, sin confusión con el uso del dinero como medio de cambio14 (Vaughn, 1983: 73-74).

En íntima relación con estas precisiones, podemos decir que los argumentos que brinda Locke en favor de la desregulación de la tasa de interés, muestran sin lugar a dudas la comprensión de la lógica del capital más allá de su forma agraria. En efecto, Locke justifica el

12 "Obstáculos al comercio: la complejidad de la ley; las detenciones; los encarcelamientos; el poder arbitrario y los vicios tendientes a la prodigalidad" (Locke, 2011: 117).

13 En este sentido, resulta destacable su propuesta de reacuñación, concebida para evitar la deflación como producto de la escasez de moneda (Laslett, 1957: 378, 386).

14 " [...] el comercio es necesario para la producción de riquezas, y el dinero es necesario para el funcionamiento del comercio" (Locke, 1999: 64). 
interés y, en especial, la desregulación de su tasa, equiparándola a la renta de la tierra. Según Locke, si consideramos legítimo cobrar una renta por el uso de la tierra como medio de producción, debemos considerar que lo es pagar interés por el dinero, pues como capital constituye también un medio de producción.

[...] en el dinero hay un valor doble, que responde en primer término a que es capaz de rendir un ingreso anual debido a su interés, y que en este sentido tiene la misma naturaleza que la tierra (el ingreso de uno se llama renta y el del otro interés) sólo con una diferencia que la tierra tiene diversos suelos (Locke, 1999: 81; véase también 84).

Como se puede apreciar, a pesar del énfasis atribuido a la crítica de las malas artes de banqueros y comerciantes (Wood, 1983: 38-39), Locke está lejos de condenar en términos de usura la tasa de interés dada en una situación de mercado. El interés que se paga por el capital monetario es tan legítimo como la renta que se paga por la tierra. La ganancia del capital financiero a través del interés es tan legítima como cualquier otra (Locke, 1999: 85). Si la ganancia de la actividad productiva fuese inferior a la tasa de interés, el capitalista no tendría motivo alguno para endeudarse. En este sentido, Locke considera tan legítima la ganancia del capital productivo como la del financiero:

Cuando el interés es muy alto dificulta la ganancia del comerciante de tal manera que no pedirá prestado; cuando es demasiado bajo impide la ganancia del inversor, de manera que éste no dará dinero en préstamo, por lo que de ambas maneras es un obstáculo para el comercio (Locke, 1999: $111)$.

Como se ve, aquí se consideran igualmente necesarias la actividad productiva y mercantil, así como el uso del dinero como capital para financiarlas. Al mismo tiempo, a tono con la tradición liberal subsiguiente, subyace la idea de un precio natural que surge de la oferta y la demanda. Locke vuelve una y otra vez sobre esta noción de precio natural, ya sea que la mercancía de que se trate sea el dinero, los bienes necesarios o innecesarios (Locke, 1999: 59).

Del mismo modo que la actividad financiera, la actividad mercantil tampoco es cuestionada. En Venditio, Locke señala que tanto la actividad productiva como la comercial implican, de por sí, obtener ganancias de las necesidades ajenas y, por lo tanto, no puede haber nada que reprocharles en este sentido. Ninguna noción de justicia distributiva debe anteponerse a los precios naturales del mercado (Locke, 2003: 443; Vaughn, 1983: 156). De hecho, Locke argumenta que de condenar las ganancias extraordinarias del comerciante en épocas de escasez, no estaríamos teniendo en cuenta que nadie cubre sus pérdidas en tiempos de abundancia (Locke, 2003: 445)15.

15 Para un análisis del salto de la solución mercantilista y regulacionista a la solución fisiocrática y liberal del problema de la escasez, véase Foucault, 2006: 48-59. El siguiente pasaje expone la crítica a la regulación que comienza con el pensamiento fisiocrático y será continuada por la tradición liberal: "Sistema antiescasez, sistema esencialmente centrado en un acontecimiento eventual, un acontecimiento que podría producirse y que se intenta impedir aun antes de que se inscriba en la realidad. No hace falta insistir en los conocidos fracasos, mi veces comprobados, de ese sistema. Fracasos consistentes en lo siguiente: en primer lugar, el mantenimiento del precio de los granos en los niveles más 
A petición de cuál es la medida que debe regular el precio por el que cualquier persona vende, con el fin de mantenerlo dentro de los límites de la equidad y la justicia, considero sucintamente que ha de ser la siguiente: el precio de mercado allí donde se vende. Todo aquel que sigue esta [norma] en todo lo que vende pienso que está libre de engaño, extorsión y opresión, o de cualquier culpa en su venta, suponiendo que no hubiera falla ${ }^{16}$ en sus productos (Locke, 2003: 442).

Locke estima que no deben fijarse límites arbitrarios a las ganancias. Sin embargo, lo más relevante aquí, como bien destaca Vaughn, es la aproximación a la idea clásica de equilibrio natural del mercado. En efecto, sobre el supuesto de la veridicción del mercado, la justicia de un precio natural dictado por la oferta y la demanda, Locke avanza hacia la idea de autorregulación, condenando toda intervención externa por parte del Estado:

La medida que es común al comprador y al vendedor es precisamente que si el uno comprara tan barato como pudiera en el mercado y el otro vendiera tan caro como pudiera allí mismo, todo el que corriera sus riesgos con las necesidades mutua y perpetuamente cambiantes de dinero y artículos en compradores y vendedores, llegaría a una cuenta bastante equitativa y justa (Locke, 2003: 445).

Vaughn, no se atreve a afirmar que aquí encontramos la idea de la mano invisible del mercado, según la cual la persecución del interés egoísta de los agentes conduce al beneficio general (Vaughn, 1983: 162). Sin embargo, esto es precisamente lo que se está afirmando. Locke explícitamente justifica la especulación comercial en la venta de un producto de primera necesidad a una ciudad hambrienta, aún cuando el mismo producto fuera vendido por el mismo comerciante en otra ciudad a valores muy inferiores -siempre y cuando no se deje morir de hambre como consecuencia de esta especulación- (Locke, 2003: 445-446; véase también Wootton, 1992: 90). El ejemplo muestra un escenario de agentes movidos por un egoísmo extremo, inmersos, sin embargo, en un equilibrio de mercado que garantiza la justicia general, sin necesidad de regulación estatal17. Recuperando la lectura foucaultiana, podríamos hablar aquí de la emergencia del homo oeconomicus:

bajos hace que, en principio, aun cuando haya abundancia de granos, o, mejor, sobre todo cuando la hay, los campesinos se arruinen, pues quien dice abundancia de granos dice tendencia de los precios a la baja, y finalmente el precio del trigo para los campesinos será inferior a las inversiones hechas por éstos para obtenerlo; por lo tanto, ganancia que tiende a cero y llegado el caso cae por debajo del costo mismo de producción para los campesinos. En segundo lugar, la segunda consecuencia será que los campesinos, al no conseguir, ni siquiera en los años de abundancia de trigo, suficiente ganancia con su cosecha, estén necesariamente condenados y forzados a sembrar poco. Cuanto menos siembren, menos ganancia tendrán y, desde luego, menos podrán sembrar. Como consecuencia inmediata de esa escasa siembra, el menor desarreglo climático, y me refiero a la más mínima oscilación del clima, un poco de frío excesivo, un poco de sequía, un poco de humedad, hará que la cantidad de trigo que es apenas suficiente para alimentar a la población caiga por debajo de las normas requeridas, y el año siguiente aparecerá la escasez" (Foucault, 2006: 50). Como acabamos de ver, Locke esgrime precisamente este argumento: es preciso respetar las ganancias extraordinarias, en la medida que no se cubren las pérdidas.

16 El término es "fallacy", su traducción literal sería "falacia".

17 En todo caso, la intervención es de la justicia penal, pero siempre a posteriori, en caso de que se hubiera cometido algún crimen de esta naturaleza. No se propone una intervención preventiva y regulatoria. 
El homo oeconomicus es quien obedece a su interés, aquel cuyo interés es tal que, en forma espontánea, va a converger con el interés de los otros. Desde el punto de vista de una teoría del gobierno, el homo oeconomicus es aquel a quien no hay que tocar. Se lo deja hacer (Foucault, 2007: $310)$.

Ahora bien, Locke no se limita a ofrecer razones normativas, en términos de justicia, para criticar la regulación de la tasa de interés ${ }^{18}$. Brinda también razones completamente empíricas, del orden de la ineficacia de una posible intervención estatal sobre el mercado. En efecto, allí donde se fijara por ley un tope a la tasa de interés, por ejemplo del cuatro por ciento, la demanda de crédito por un lado, y las artes del capital financiero por el otro, en especial de los banqueros "de Londres", harían que la regulación de la tasa de interés no resulte exitosa. El interés podría elevarse no sólo por encima del precio que establece la regulación estatal sino incluso por sobre el precio natural, dado que ahora debe añadírsele el costo del riesgo que supone la ilegalidad (Locke, 1999: 55-56).

Sin embargo, esta propuesta de dejar hacer a los diferentes agentes empresarios, no debe confundirse con una completa ausencia de la intervención del Estado en la economía. El rol del Estado es, por supuesto, proteger la propiedad privada, pues éste es el fin de la sociedad civil (T. T., II, §138, 139-140, 142, §131, §222). Pero también se extiende a proteger las arcas públicas, fundamentalmente garantizando que las exportaciones sean siempre mayores que las importaciones (Locke, 1999: 119). Este elemento mercantilista o, más precisamente, este rasgo de nacionalismo económico (puesto que no atribuye la fuente de la riqueza a la acumulación de reservas sino al trabajo y la producción), en modo alguno invalida los elementos claramente liberales que se han consignado hasta aquí.

En efecto, cuando Locke plantea una política de control de la balanza comercial para no desequilibrar las arcas públicas, en modo alguno señala que la actividad mercantil sea por sí misma fuente de riqueza o que la riqueza consista en acumular reservas. "La única manera, y la más segura de que la nación se enriquezca, es gastar menos de lo que nuestras propias mercancías pueden pagar" (Locke, 1999: 119). Esta afirmación debe ser leída a la luz de la consideración sobre la doble acepción de comercio que hemos destacado. En efecto, aquí en modo alguno se cambia el eje de la fuente de la riqueza del "comercio", entendido como desarrollo del ciclo productivo completo. Las apreciaciones de Locke apuntan en todo momento a estimular la actividad productiva, la cual es la verdadera fuente de la riqueza, sin perder de vista que esa producción se realiza en competencia con otras potencias, especialmente España y Holanda, en pugna por el mercado mundial de consumidores.

En este sentido deben tomarse los ejemplos brindados sobre Holanda como potencia emergente. Locke argumenta que la fuente de la riqueza en Holanda no es otra que la productividad del trabajo y su frugalidad como consumidores. Ello les permite a los productores holandeses, por ejemplo, comprar materias primas en Inglaterra, manufacturarlas en Holanda y revenderlas en Inglaterra conservando un margen de ganancia (Locke, 1999: 126). El riesgo para Locke es que una mala política en cuanto a la balanza comercial haga

18 Locke argumenta, por ejemplo, que aún en los períodos en que el interés del capital fue del diez por ciento, los comerciantes adaptaron sus precios de modo tal de poder obtener ganancias superiores al interés: por lo tanto la alta tasa de interés, por sí misma, no es capaz de arruinar a ningún comerciante (Locke, 1999: 125-126). 
que Holanda le gane mercados a Inglaterra: "Porque las corrientes del comercio, como las de las aguas, se transforman en canales, de los cuales después es difícil desviarse" (Locke, 1999: 64).

La consideración de las variables económicas (cuál es la tasa legítima de interés, cuál es la carga impositiva que debe tener el comercio y la propiedad de la tierra, cuál ha de ser el usufructo de las colonias, cómo debe administrarse el comercio exterior), tiene lugar en el contexto de esta disputa internacional. Pero lejos de tratarse de un elemento contrario al liberalismo, podría incluso considerarse como definitorio del mismo. Así lo hace al menos Foucault: “[...] veridicción del mercado, limitación por el cálculo de la utilidad gubernamental y, ahora, posición de Europa como región de desarrollo económico ilimitado con respecto a un mercado mundial. Esto es lo que llamé liberalismo" (Foucault, 2007: 81)19.

En el apartado siguiente veremos que este dejar hacer a los industriosos y racionales se articula con una fuerte regulación destinada a crear un mercado laboral. En este sentido, resulta cuestionable la distinción que hace Foucault entre un liberalismo que no implicaría intervención alguna, y un neoliberalismo caracterizado por la regulación permanente con vistas a crear condiciones para la libre actividad del mercado. Por el contrario, veremos que desde un comienzo el liberalismo supuso regulación estatal (Foucault, 2007: 155-158)20.

\section{Hacer vivir como disciplinamiento de la fuerza de trabajo}

La ley se refiere siempre a la espada. Pero un poder que tiene como tarea tomar la vida a su cargo necesita mecanismos continuos, reguladores y correctivos. Ya no se trata de hacer jugar la muerte en el campo de la soberanía, sino de distribuir lo viviente en un dominio de valor y de utilidad. Michel Foucault 21

19 “[...] los europeos serán los jugadores y, pues bien, el mundo será la apuesta. El juego está en Europa, pero la apuesta es el mundo [...]. La colonización había comenzado mucho tiempo atrás. No creo tampoco que allí se sitúe el comienzo del imperialismo en el sentido moderno o contemporáneo del término [...]. Digamos, no obstante, que allí tenemos los inicios de un nuevo tipo de cálculo planetario en la práctica gubernamental europea" (Foucault, 2007: 74).

20 "El neoliberalismo, entonces, no va a situarse bajo el signo del laissez-faire sino, por el contrario, bajo el signo de una vigilancia, una actividad, una intervención permanente" (Foucault, 2007: 158). En efecto, como el propio Foucault había advertido en su análisis de los dispositivos de seguridad, propios de la policía, la regulación sobre las poblaciones es permanente y constante: "En términos concretos, ¿qué deberá ser la policía? Y bien, deberá asignarse como instrumento todo lo que sea necesario y suficiente para que la actividad del hombre alcance una integración efectiva al Estado, a sus fuerzas, al desarrollo de éstas, y deberá procurar que el Estado, a cambio, pueda estimular, determinar, orientar esa actividad de una manera eficaz y útil para sí mismo. En una palabra, se trata de la creación de la utilidad estatal, a partir y a través de la actividad de los hombres. Creación de la utilidad pública a partir de la ocupación, la actividad, a partir del quehacer de los hombres" (Foucault, 2006: 370). Si reconocemos la simultaneidad de estos mecanismos de seguridad con la emergencia del liberalismo, entonces resulta difícil leer al liberalismo como mero "dejar hacer" a partir de la lectura literal y basada en el discurso teórico, y no en las prácticas efectivas, como las que detallaremos a continuación.

${ }^{21}$ Foucault, 2005a: 174. 
El derecho a los medios de subsistencia es una constante en los escritos lockeanos. En efecto, aparece en $T$. T., I, §41-42 en términos de caridad, en $T$. T., II, §25-28 como derecho de todos los hombres a la apropiación de los frutos ${ }^{22}$, aparece en la condena, en términos de asesinato, del accionar del comerciante cuya especulación condujera a dejar morir de hambre en Venditio (Locke, 2003: 445), en SC estableciendo que el hambre de los trabajadores es el motivo para la resistencia (Locke, 1999: 118) así como a lo largo del desarrollo de su propuesta de una nueva ley de pobres (Draft), que estudiaremos a continuación. Esta exigencia de proveer los medios de subsistencia no es meramente un deber del propietario sino un derecho de los necesitados. Quien no cumpliera con "los derechos de los pobres al fallar en proveer sus necesidades cuando carecen de otros medios de subsistencia" estaría "violando la mismísima ley de naturaleza", la cual es la que le otorga en primer lugar "derecho a su propiedad" (Waldron, 1979: 326) 23.

[...] la caridad da derecho a cada hombre a aquella parte de los bienes superfluos de los demás necesarios para librarle de la extrema necesidad mientras no tenga otros medios para subsistir: y tan injusto es que un hombre haga uso de la necesidad de otro para forzarle a convertirse en su vasallo reteniendo aquella ayuda que Dios le exige proporcionar a las necesidades de su hermano, como el que un hombre fuerte se apodere del débil, le fuerce a obedecerle, y poniéndole un puñal en el pecho, le dé a elegir entre la muerte y la esclavitud (T. T. I, §41-42).

La caridad constituye tanto una obligación del propietario como un derecho del necesitado, pero no en el sentido de una prerrogativa que habilite al necesitado a tomar los bienes que un propietario poseyera en abundancia ${ }^{24}$. En este sentido, hay que subrayar que la caridad siempre es invocada en la situación extrema en que una persona no cuenta con los medios de subsistencia (Marshall, 1994: 297). Se trata entonces de un derecho sobre los frutos, que no implica ningún tipo de distribución forzosa o estructural, por ejemplo de la propiedad de la tierra, que para Locke es "la cuestión principal acerca de la propiedad" (T. $T$., II, §32).

De aquí que en el comienzo del parágrafo 43 de $T$. T., I, inmediatamente a continuación del pasaje citado, Locke censure el carácter "cruel" y falto "de caridad" del terrateniente que

\footnotetext{
22 Véase Buckle, 2001: 247-248.

23 Sigmund sigue la línea argumental de Waldron, considerando la impronta teológico-cristiana de la fundamentación de la teoría de la propiedad lockeana, con el fin de derivar una idea de equidad (Waldron, 2002a; Sigmund, 2002: 408, 41; Dunn, 1969: 219; Tully, 1980: 109, 122; también Dunn 2002; Boyd, 2002; contra esta interpretación, Chumbita, 2013a).

24 En este sentido, la noción de caridad que maneja Tomás, contrariamente a la interpretación de Waldron (1979: 326-327) y Tully (1980: 132) es radicalmente diferente a la de Locke: “[...] aquello que algunos poseen en superabundancia se debe, por ley natural, al propósito de socorrer a los pobres [...]. Cada uno se encarga de la administración de sus propias cosas, por lo que se puede recurrir a ellos [los propietarios] para ayudar a los necesitados. Pero si la necesidad resulta tan manifiesta y evidente que la necesidad presente se tiene que remediar por cualquier medio a la mano [...] entonces es legítimo para un hombre satisfacer sus propias necesidades por medio de la propiedad de otro, tomando ya sea abiertamente o en secreto, sin constituir esto un hurto o robo" (Summa Theologica, II, II, 66. 7, en Waldron, 1979: 327). Para una revisión crítica de la interpretación de Waldron sobre el lugar que ocupa la caridad en la teoría de la propiedad, véase Chumbita, 2013a.
} 
indujera al pobre a trabajar en servidumbre tomando provecho de su situación de extrema necesidad. Sin embargo, aclara que "la sumisión del mísero mendigo no nace de la presión del señor, sino del consentimiento del pobre hombre, que prefiere ser súbdito a morirse de hambre" (T. T., I, §43). Es decir que la posibilidad de cambiar el pan por trabajo servil es al mismo tiempo condenada moralmente, como legitimada por la aquiescencia del pobre, aún cuando el pacto se celebrara en condiciones de necesidad extrema.

En este sentido, la contraprestación de trabajo, como correlato necesario a la garantía del derecho a la subsistencia, es una de las premisas fundamentales de la propuesta lockeana de Draft. Para entender esta propuesta, que resultó rechazada por ser no sólo menos progresista que otras propuestas de la época sino más punitiva que la legislación existente (Becker, 1992: 655-65625; Wootton, 1992: 87), es preciso considerar sus dos supuestos básicos. En primer lugar, el reconocimiento de un derecho casi universal a la vida (digo casi universal porque el esclavo no tiene ese derecho ${ }^{26}$ ). En segundo lugar, la necesidad de introducir un cálculo de costo beneficio, con el fin de reducir la carga que supone para las arcas públicas la manutención de los pobres 27.

En este sentido, Vaughan señala lo paradójico que resulta, al interior del planteo lockeano, que siendo la causa de la pobreza el vicio y la ociocidad de los propios pobres, la sociedad civil en su conjunto deba costear su subsistencia (Locke, 2003: 447; Vaughan, 2002: 6). ${ }^{28}$ La razón de ello radica precisamente en el reconocimiento del derecho a la vida:

\footnotetext{
25 "Mientras los progresistas de la época abogaban por la despenalización de la pobreza en el trato con los desempleados, Locke propuso una nueva legislación penal que resultaba severa incluso para la época [...]. Los niños encontrados mendigando iban a ser enviados a las escuelas de trabajo propuestas por él, en las que pudieran ser «azotados razonablemente y mantenidos en el trabajo hasta la tarde». Para los hombres desempleados, la respuesta era el reclutamiento forzoso en la Marina, a excepción de los que fueran demasiado viejos o discapacitados. Estos hombres recibirían tres años de cárcel. La mutilación física estaba reservada para los falsificadores de pasaporte, que habrían de «perder sus oídos». Locke también considera que los pobres que recibieran la liberación debían llevar insignias identificatorias" (Becker, 1992: 655-656).

26 El esclavo es el cautivo de una guerra justa, condenado a la pena capital ( T. T., II, $\S 23-24$, $\S 85$, véase también §172, §174; Locke, 2003, 230: §107, §100). Para un análisis de la noción de esclavitud en T. T. véase Chumbita, $2013 \mathrm{~b}$.

27 Para evitar confusiones mantendremos aquí la traducción literal del término «poor», por pobre. Sin embargo, es preciso aclarar que su significado se adecúa mejor a la definición actual de indigente, puesto que se refiere a quien se halla en una situación de extrema necesidad, siendo incapaz de proveerse por sí mismo de los medios de subsistencia. En efecto, si bien esta ley se propone realizar ciertas metas que van más allá de resolver la indigencia, el sujeto al que se dirige no se corresponde con una definición de pobre en términos de quien posee ciertas necesidades básicas insatisfechas (como por ejemplo educación, agua potable, asistencia médica, etc.) sino a aquel que no es capaz de proveerse de los medios de subsistencia.

28 "El crecimiento de los pobres debe por tanto tener alguna otra causa, y esta causa no puede ser sino la relajación de la disciplina y la corrupción de las costumbres; la virtud y la industria permanecen como compañeros constantes por un lado, así como el vicio y la ociosidad lo hacen por el otro" (Locke, 2003: 447). Pocock y Ashcraft, intentan justificar la asociación entre propiedad y virtud en términos históricos (Pocock y Ashcraft, 1980: 16).
} 
Todos deben tener carne, bebidas, ropa y lumbre. Mucho de esto sale de los fondos del reino, tanto si los pobres trabajan, como si no. Suponiendo, entonces, que hay 100.000 pobres en Inglaterra, que viven de la parroquia, es decir, que son mantenidos por el trabajo de otras personas (porque esto es lo que sucede con todos aquellos que viven de las limosnas sin trabajar), si se tomara la precaución de que cada uno de ellos, bien sea trabajando en la fabricación de lana o en otra manufactura, ganara 1 penique por día (lo que, unos como otros, bien podrían hacer, y más), esto podría suponer para Inglaterra 130.000 libras esterlinas por año, que en ocho años haría a Inglaterra más de un millón de libras más rica (Locke, 2011: 200-201).

Como se puede apreciar en este pasaje, la propuesta de solvento de la pobreza, implica tanto una dimensión normativa como de cálculo de costo beneficio ${ }^{29}$. En este sentido, queda claro que si la mejor política para el capital es dejar hacer, puesto que en el mercado prevalecerán los mejores capitalistas, aún a costa de la ruina de algunos o muchos de ellos, en cuanto al trabajo se requiere una intervención sumamente regulada por parte del Estado: el bien público no se obtiene aquí espontáneamente. Si todos tienen derecho a comer, todos tienen a su vez la obligación de trabajar. Y en este sentido, el objetivo general que Locke se propone es el pleno empleo de las fuerzas productivas.

La propuesta de ley establece que el trabajo será libre para quien lo solicite y forzado para quien lo rehuya. "Que también las personas maduras, para eliminar su aparente intención de búsqueda de trabajo, puedan ir a las mencionadas escuelas de trabajo a aprender, donde en consecuencia les será proporcionado trabajo" (Locke, 2011: 206, §17). Locke propone así una serie de normas destinadas a los funcionarios públicos y a los empresarios locales, para garantizar que quien solicite trabajo y esté dispuesto a trabajar, lo obtenga aún a cambio de un salario menor (acorde con el argumento de que si efectivamente el trabajo del pobre valiera el salario real, ya hubiese encontrado un puesto por sus propios medios).

Que el custodio de los pobres de la parroquia donde se reclama trabajo, el domingo siguiente después de serle presentada la queja, deberá dar a conocer a la parroquia que tal persona quiere trabajar, y luego preguntar si alguien está dispuesto a emplearle a una tarifa menor de la pagada usualmente [...]. Pero si nadie en la parroquia acepta de forma voluntaria a tal persona a la tarifa propuesta por el custodio de los pobres, entonces estará en poder de dicho custodio, con el resto de la parroquia, hacer una lista de días, según la proporción de impuestos que todos pagan para los pobres, y que, de acuerdo con dicha lista, cada habitante de la parroquia estará obligado a emplear a los hombres pobres desempleados de la misma, según las sub-tarifas que el custodio designará; y, si alguno rehusara emplear en su turno a un pobre, deberá pagar el salario acordado, tanto si lo emplea realmente como si no (Locke, 2011: 198-199, §9).

La obligación de dar trabajo se corresponde perfectamente con la definición de la caridad como derecho del necesitado y obligación del propietario (T. T., I, §42-43). En este mismo sentido, para quienes posean las propiedades más ricas de la región, se establece la obligación de tomar como aprendices a niños pobres de las escuelas de trabajo. Para los terratenientes se estipula que deberán tomar a un niño como aprendiz de labranza cuando sus rentas anuales fueran superiores a $£ 25$. La contraprestación debe durar en todos los casos

${ }^{29}$ La intención de preservación de las arcas públicas se advierte también, por ejemplo, en la propuesta de políticas de consumo local para la producción de las casas de trabajo en que deberían ser recluidos los indigentes (Locke, 2011: 206, §18). 
hasta que el aprendiz cumpla la edad de veintitrés años (Locke, 2011: 205, §15). Lo mismo se establece para los artesanos (Locke, 2011: 205, §14) y también para el arrendatarios que tuviera la propiedad más extensa, hasta lograr que todos los niños de las casas de trabajo fueran empleados (Locke, 2011: 206, §16). Del mismo modo se establece:

Que todos los capitanes de los buques del rey deban estar obligados a recibir, sin obtener dinero a cambio, una vez al año (si se lo propone el magistrado o cualquier otro funcionario dentro de los límites del puerto donde podría estar su buque) un niño, con el cuerpo sano, mayor de 13 años de edad, quien será su aprendiz por el plazo de nueve años (Locke, 2011: 213, §40).

Entre aquellos que no se ofrecen voluntariamente a trabajar, Locke distingue tres tipos: los que por edad o discapacidad no pueden trabajar y deben recibir manutención sin contraprestación; los que pueden contribuir, aún cuando no cubran por completo su manutención y los que pueden hacerlo pero no lo hacen por indolencia. Excepto los primeros, todos deben ser recluidos en las casas de trabajo, en buques de altamar o en las casas de corrección. Los pobres hallados mendigando sin autorización debían ser aprehendidos en el momento (lo cual ya estaba penado por la legislación vigente ${ }^{30}$ ).

[...] todos los hombres saludables de cuerpo y mente, mayores de 14 y menores de 50 años de edad, que mendiguen en condados marítimos fuera de su propia parroquia sin un pase, deban ser capturados por cualquier funcionario de la parroquia donde lo estuviesen haciendo, (funcionarios que, en virtud de su cargo, deben ser autorizados, y en virtud de una pena obligados a hacerlo), o por los habitantes de las casas donde pidieron limosna (Locke, 2011: 195).

La pena para el mendicante en un condado marítimo consistiría, según la propuesta de ley lockeana, en la permanencia durante tres años en uno de los "buques de su majestad" para servir "bajo una estricta disciplina, a la remuneración de soldados" de las cuales les "serán deducidas las dietas de subsistencia para el pago de sus víveres a bordo" recibiendo el castigo correspondiente a "desertores" si transitaran "por la costa sin permiso" o durante más tiempo del concedido (Locke, 2011: 195-196). ${ }^{31}$ Aquellos que mendigaran en condados que no fueran marítimos debían ser enviados a las casas de corrección, donde se los mantendría "a trabajos forzados durante tres años" (Locke, 2011: 196). Las mujeres tendrían períodos de reclusión más breves, pero siempre serían transportadas a las casas de corrección de sus condados de nacimiento (Locke, 2011: 197-198).

\footnotetext{
30 Foucault refiere a estas políticas como parte del gran encierro, propias del siglo XVII y caracterizadas por "la lógica del trabajo obligatorio" para aquellos que, paradójicamente, no podían trabajar (Foucault, 1999: 92). Este régimen de trabajo forzado se volvería contraproducente al desarrollo del capitalismo durante el siglo XIX. En efecto, para la construcción de un mercado laboral autorregulado, en el que se compitiera bajo la modalidad de asalariado libre, el hecho de tener garantizada la subsistencia constituía un obstáculo (Polanyi, 2011: 92, 94).

31 En el mismo sentido, deben entenderse las recomendaciones de Locke para la colonia de Virginia, en su calidad de Commissioner de la Board of Trade. Según Locke, a fines de poblar la colonia para el incremento de su productividad deberían enviarse allí a los pobres de Inglaterra (Ashcraft, 1969: 747). Es preciso recordar que este cargo no tenía atribuciones ejecutivas, sino que funcionaba como órgano de asesoramiento (Laslett, 1957: 372).
} 
La propuesta de ley estipula a su vez que todo niño, varón o mujer, menor de 14 años que fuera hallado mendigando a cinco millas fuera de su parroquia "deberá ser enviado a la escuela de trabajo más cercana, donde será severamente azotado, y mantenido trabajando hasta el anochecer, de manera que pueda salir con tiempo suficiente para llegar a su lugar de residencia esa misma noche" durante un período de seis semanas (Locke, 2011: 198). Por su parte, los hijos de quienes solicitan la ayuda de las parroquias (según la legislación vigente) deberían ser obligados, según la reforma propuesta, a asistir a escuelas de trabajo. Esta normativa sería válida para todos los niños mayores de tres y menores de catorce años y su objeto consistiría en evitar la mediación de los padres en la asistencia a los niños, a fin de evitar posibles desvíos de la ayuda económica a otros fines (Locke, 2011: 202).

En este sentido, Locke explica que el fin del trabajo de los niños a partir de la edad de tres años no es que solventen sus gastos, sino que contribuyan en la medida de sus posibilidades, erradicando de este modo el hábito de la ociocidad y el vicio de sus padres: "No suponemos que los niños de 3 años serán capaces, a esa edad, de obtener sus medios de subsistencia en la escuela de trabajo, pero estamos seguros de que lo necesario para su asistencia será más eficaz si se distribuye el pan en la escuela que si se le da a su padre en dinero" (Locke, 2011: 203). Al mismo tiempo, se espera que la asistencia a las casas de trabajo sirva a su formación en oficios (que luego se traduciría en colocaciones de trabajo libre, como ya hemos visto): "de ese modo será mayor la obligación de asistir a la escuela y aplicarse al trabajo" "aumentando cada día los ingresos de su trabajo en la escuela". Esto permitirá, según la propuesta, que "la alimentación y la enseñanza de esos niños durante todo ese tiempo no costaran nada a la parroquia", en contraposición a los costos vigentes según los cuales "un niño que es mantenido por la parroquia desde su nacimiento hasta la edad de 14 años, tiene un costo para esta de $£ 50$ o £60" (Locke, 2011: 203-204).

Foucault interpreta este tipo de regulaciones como propias del mercantilismo, las cuales perderían vigencia bajo el paradigma liberal ${ }^{32}$. Sin embargo, no es esta la interpretación que se hace aquí. En el caso de Locke, lo que se advierte no es una oposición entre un siglo XVII regulacionista y mercantilista y unos siglos XVIII y XIX liberales y anti-regulacionistas, sino más bien, en el seno del liberalismo lockeano, una articulación entre regulación del trabajo y dejar hacer al capital. Como dirá el propio Foucault respecto al liberalismo del siglo XIX, no se trata de garantizar libertades sino de producir este tipo particular de libertad, la cual implica imponer "limitaciones, controles coerciones, obligaciones apoyadas en amenazas" (Foucault, 2007: 84) ${ }^{33}$.

\footnotetext{
32 "Para situarse en la base de la riqueza y el poder del Estado, la población debe estar, por supuesto, regimentada por todo un aparato reglamentario que impedirá la emigración, atraerá a los inmigrantes y favorecerá la natalidad; un aparato reglamentario, asimismo, que va a definir cuáles son las producciones útiles y exportables, que va a determinar además los objetos que deben producirse, los medios para producirlos y los salarios, y que va a prohibir la ociosidad y el vagabundeo [...] la población como fuerza productiva, en el sentido estricto de la expresión, era la preocupación del mercantilismo y me parece que después de los mercantilistas, en el siglo XVIII y menos aún en el siglo XIX, desde luego, ya no se la juzgará esencial y fundamentalmente con ese carácter" (Foucault, 2006: 91; véase también Foucault, 2007: 158).

33 "Si empleo el término liberal es ante todo porque esta práctica gubernamental que comienza a establecerse no se conforma con respetar tal o cual libertad, garantizar tal o cual libertad. Más profunda-
} 
De este modo, es posible distinguir el liberalismo clásico del liberalismo lockeano. En efecto, no podemos atribuir a Locke la idea de un mercado de trabajo autorregulado del siglo XIX. En las propuestas económicas y sociales lockeanas que hemos considerado, el dejar hacer a los industriosos y racionales se combina con la necesidad de producir cuerpos dóciles. Si bien ya encontramos la idea de que el precio justo es el dictado por el mercado, incluso cuando la mercancía es el trabajo, aún así subsiste la necesidad de poner en marcha todas las fuerzas productivas de la nación. En este sentido, no basta con dejar hacer a un supuesto mercado laboral, sino que es preciso construirlo.

La propuesta de Draft supone, como hemos visto, un riguroso sistema regulativo y disciplinario. Esto nos permite recuperar la pertenencia de las disciplinas y los dispositivos de seguridad a una misma lógica biopolítica (Foucault, 2005a: 16834). En efecto, el modesto derecho a la vida, que surge del derecho a los medios de subsistencia en situación de extrema necesidad ${ }^{35}$, se transforma inmediatamente en intervención estatal para construir una fuerza laboral presuntamente al servicio del enriquecimiento de la nación, con una indudable dimensión criminalizadora de la pobreza y disciplinadora de los sectores populares. Apropiándonos de la terminología foucaultiana, podemos decir que, a través de la articulación de las disciplinas y dispositivos de seguridad aquí consignados, se advierte el pasaje del paradigma de la soberanía, hacer morir y dejar vivir, hacia el paradigma biopolítico de

mente, es consumidora de libertad [...]. Consume libertad: es decir que está obligado a producirla. Está obligado a producirla y está obligado a organizarla" (Foucault, 2007: 83-84). Considérese, en este sentido, el siguiente ejemplo histórico de intervención liberal y regulacionista durante el siglo XIX, citado por el propio Foucault, para producir condiciones de marcado: "los gobiernos norteamericanos, por ejemplo, que sin embargo se valieron de ese problema para rebelarse contra Ingalterra, establecerán desde comienzos del siglo XIX tarifas aduaneras proteccionistas para poner a salvo una libertad de comercio que la hegemonía inglesa compromete. Lo mismo sucede con la libertad de mercado interno [...]. Necesidad, por consiguiente, si hace falta, de sostener el mercado y crear compradores por medio de mecanismos de asistencia. Para que haya libertad de mercado interno no debe haber efectos monopólicos. Necesidad de una legislación antimonopolista. Libertad del mercado de trabajo, pero es preciso asimismo que haya trabajadores, un número bastante grande trabajadores, lo suficientemente competentes y calificados, y que carezcan de armas políticas para que no puedan ejercer presión sobre el mercado liberal [...] producción de la libertad necesaria, precisamente, para gobernar". "Por lo tanto, la libertad en el régimen del liberalismo no es un dato previo, no es una zona prefabricada que haya que respetar o, si lo es, sólo lo es parcialmente, regionalmente, en tal o cual caso, etc. La libertad es algo que se fabrica a cada instante" (Foucault, 2007: 85).

34 "Concretamente, ese poder sobre la vida se desarrolló desde el siglo XVII en dos formas principales; no son antitéticas; más bien constituyen dos polos de desarrollo enlazados por todo un haz intermedio de relaciones. Uno de los polos, al parecer el primero en formarse, fue centrado en el cuerpo como máquina: su educación, el aumento de sus aptitudes, el arrancamiento de sus fuerzas, el crecimiento paralelo de su utilidad y su docilidad, su integración en sistemas de control eficaces y económicos, todo ello quedó asegurado por procedimientos de poder característicos de las disciplinas: anatomopolítica del cuerpo humano [...]. Las disciplinas del cuerpo y las regulaciones de la población constituyen los dos polos alrededor de los cuales se desarrolló la organización del poder sobre la vida" (Foucault, 2005a: 168).

35 Refiriéndose a la anulación de la legislación general sobre la ley de pobres, durante la primera mitad del siglo XIX, Polanyi hablará de "abolición del «derecho a la vida»", en la medida en que la ley de pobres garantizaba un subsidio semanal del valor del pan para los pobres: “[...] bajo el nuevo régimen del hombre económico [homo oeconomicus], nadie trabajaría por un salario si podía vivir sin hacer nada" (Polanyi, 2011: 129). 
hacer vivir y dejar morir en el seno del siglo XVII (Foucault, 2006: 19-20). En este sentido, el dejar hacer a los industriosos y racionales y el hacer vivir de los pobres, es presentado bajo un mismo objetivo: el de multiplicar la riqueza del país.

\section{Conclusiones}

Como hemos podido ver, la lectura de $S C$ y Draft permite identificar una serie de actores sociales y económicos que no se advierten en las formulaciones general de $T$. $T$., II. En este sentido, su estudio permite comprender mejor la centralidad de la propiedad privada en la teoría política lockeana. En efecto, la puesta en relación entre desarrollo económico y bien común, requiere por un lado dejar hacer a los agentes empresarios, tanto del capital agrario, como manufacturero, mercantil y financiero y, por el otro, proteger la balanza comercial en la competencia con otras potencias del mercado mundial. Al mismo tiempo, la consideración de la propuesta lockeana de Draft da cuenta de las políticas de disciplinamiento y regulación de los trabajadores, así como de la reducción de sus derechos al derecho a la subsistencia. De este modo, a la luz de la articulación entre la liberalización protegida del capital y la restricción y disciplinamiento del trabajo, se comprende de un modo más acabado por qué el fin de la sociedad civil en $T$. T., II es para Locke la protección de la propiedad privada.

\section{Referencias bibliográficas}

AshCRAFt, R. (1969), "Political Theory and Political Reform: John Locke's Essay on Virginia", The Western Political Quarterly, vol. 22, N 4, (Dec., 1969), pp. 742-758.

BECKER, R. (1992), "The ideological commitment of Locke: Freemen and servants in the Two Treatises of government". History of Political Thought, Vol. 13, N 4, pp. 631-656.

Buckle, S. (2001), "Tully, Locke and America" British Journal for the History of Philosophy, 9 (2), pp. 245-281.

ChumbitA, J. (2011), "El desplazamiento en la teoría de la propiedad de John Locke: del criterio de necesidad a la teoría del valor para justificar la colonización inglesa en América", Mendoza, Cuyo. Anuario de filosofía Argentina y Americana, vol. 28, pp. 93-120.

ChumbitA, J. (2013a), "La caridad como administración de la pobreza", Identidades, Revista del Instituto de Estudios Sociales y Políticos de la Patagonia, No 4, junio, pp. 1-21.

Chumbita, J. (2013b), "Un análisis de las nociones de abundancia y esclavitud para reinterpretar el carácter universal de la teoría de la apropiación de John Locke”, Las torres de Lucca, $\mathrm{N}^{\circ}$ 2, enero-junio, pp. 69-83.

Chumbita, J. (2014a), “Teología política, libertad natural, paz relativa y secularización en el estado de naturaleza descrito por John Locke", Bajo palabra, $\mathrm{N}^{\circ}$ 9, enero (en prensa).

Chumbita, J. (2014b), "La resistencia social como configuración del pueblo según John Locke", Revista SAAP, Vol. 8, N 1, mayo (en prensa).

Chumbita, J. (2014c), “Apropiación privada de la tierra y derechos políticos en la obra de John Locke”, Ingenium. Revista electrónica de pensamiento moderno y metodología en historia de las ideas, Vol. 8 (en prensa). 
Dunn, J. (1969), The political thought of Jonn Locke. An historical account of the argument of the "Two Treatises of government", Cambridge University Press, Cambridge.

DunN, J. (2002), "What History Can Show: Jeremy Waldron's Reading of Locke's Christian Politics", The Review of Politics, University of Notre Dame, pp. 433-450.

Dussel, E. (2007), Política de la liberación I: Historia mundial y crítica, Trotta, Madrid, pp. 269-282.

Foucault, M. (1999), Estética, ética y hermenéutica. Obras esenciales volumen III (tr. Ángel Gabilondo), Paidós, Barcelona.

Foucault, M. (2005a), Historia de la sexualidad I. La voluntad de saber (tr. Ulises Guiñazú), Siglo XXI, Buenos Aires.

Foucault, M. (2005b), El poder psiquiátrico (tr. Horacio Pons), FCE, Buenos Aires.

Foucault, M. (2006), Seguridad, territorio y población (tr. Horacio Pons), FCE, Buenos Aires.

Foucault, M. (2007), El nacimiento de la biopolítica (tr. Horacio Pons), FCE, Buenos Aires.

Glausser, W. (1990), "Three Approaches to Locke and the Slave Trade". Journal of the History of Ideas. Vol. 51. No. 2 (Apr. - Jun.), pp. 199-221.

LASLetT, P. (1957) "John Locke, the Great Recoinage, and the Origins of the Board of Trade: 1695-1698", The William and Mary Quarterly, 14 (3), Third Series (julio), pp. 370-402.

Locke, J. (1824), Works of John Locke in Nine Volumes, Rivington, Londres.

Locke, J. (1999), Escritos monetarios (tr. María Olaechea), Pirámide, Madrid.

Locke, J. (2003), Political writings (ed. D. Wootton), Hackett Publishing Company, Indianapolis/Cambridge.

LOCKE, J. (2011), Ensayo sobre la tolerancia y otros escritos sobre ética y obediencia civil (tr. Blanca Rodríguez López y Diego A. Fernández Peychaux), Minerva, Madrid.

Macpherson, C. B. (1970), La teoría política del individualismo posesivo. De Hobbes a Locke (tr. J.-R. Capella), Fontanella, Barcelona.

Marshall, J. (1994), John Locke. Resistance, religion and responsibility, Cambridge University Press, Cambridge.

MARX, K. (1999), El capital (Wenceslao Roces), Tomo I, FCE, México.

POlANYI, K. (2011). La gran transformación. Los orígenes políticos y económicos de nuestro tiempo (tr. Eduardo L. Suárez), FCE, Buenos Aires.

Pocock, J. G. y AsHCRAft, R. (1980), John Locke: Papers read at a Clark Library Seminar, 10 December, 1977, William Andrews Clark Memorial Library, University of California, Los Angeles.

Sigmund, P. E. (2002), "Jeremy Waldron and the Religious Turn in Locke Scholarship", The Review of Politics, University of Notre Dame, pp. 407-418.

Strauss, L. (1992), Natural Right and History, Chicago University Press, Chicago.

Tully, J. (1980), A discourse on Property: John Locke and Adversaries, Cambridge University Press, Cambridge

VAughn, K. (1983), John Locke, economista y sociólogo, FCE, México.

WALdron, J. (1979), "Enough and as Good Left for Others". Philosophical Quarterly. 29, pp. 319-328. 
Waldron, J. (2002a), God, Locke and Equality: Christian Foundations in Locke's Political Thougth, Cambridge University Press, Cambridge.

Waldron, J. (2002b), "Response to Critics", The Review of Politics, University of Notre Dame, pp. 495-513.

Wood, N. (1983), John Locke and Agrarian Capitalism, University of California Press, Berkeley.

Wootton, D. (1992), "John Locke and Richard Ashcraft's Revolutionary Politics", Political Studies, Vol. 40, March 1992, XL, pp. 79-98.

Joan Severo Chumbita

Universidad de Buenos Aires (Argentina)

joanchumbita@gmail.com 